\title{
Treatment of airway obstruction by metallic stents in infants and children
}

\author{
Itzhak Vinograd, MD, ${ }^{\text {a }}$ Sergei Keidar, ${ }^{\text {a Marc Weinberg, }}{ }^{\text {a }}$ and Aviel Silbiger ${ }^{\text {b }}$
}

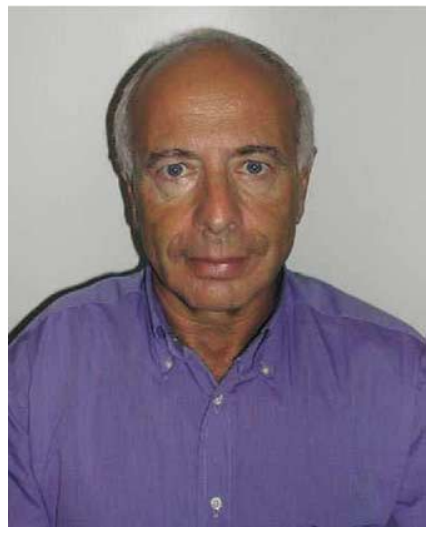

Dr Vinograd
Objective: The internal metallic stent is a relatively new and controversial method for the treatment of airway collapse in infants and children. The study examined the outcomes of this treatment in a large group of patients and defined clear indications for airway stenting.

Methods: A retrospective review was conducted of 32 patients in whom 42 stents were inserted. The patients were divided into three groups with respect to the stented segment: group A, trachea $(\mathrm{n}=14)$; group $\mathrm{B}$, bronchi $(\mathrm{n}=16)$; and group $\mathrm{C}$, trachea and bronchi $(\mathrm{n}=2)$.

Results: In 30 cases, there was immediate improvement of respiratory obstruction, and 23 patients could be weaned, at least temporarily, from ventilation. Excessive granulation developed after the stenting in 26 patients. In 6 patients, all in group A, the granulation and inflammatory reaction generated severe airway obstruction, necessitating thoracotomy in 2 cases. One patient died of airway obstruction, and another died during the attempt to remove the stent; both were in group A. Stents placed for 2 to 72 months (mean 8.7 months) have now been removed in 11 patients. Six children are alive and well with stents in place, 2 from group A and 4 from group B. Fifteen patients died during the follow-up period; in 13 cases, death was related to the associated disease.

Conclusion: The use of metallic stents, especially in the trachea, is associated with a high rate of complications. Granulation tissue, which often develops after stenting, is a major concern. Removal of the stents is arduous and carries a high risk of complications. The use of stents should be restricted to the limited situations in which conventional initial therapy has failed.

1 irway obstruction in infants and children is a challenging problem. Many surgical techniques have been suggested to stabilize the narrowed airway lumen, although none of them is universally accepted. The concept of stent implantation for airway obstruction was first introduced by Filler and colleagues ${ }^{1,2}$ in 1992, then later by others in much smaller groups of patients, with balloonexpandable metallic stents, ${ }^{3-6}$ shape memory stents, ${ }^{7,8}$ or self-expanding endobronchial stents. ${ }^{9}$ The preliminary results seemed promising; however, through the years there were increasing numbers of reports of technical difficulties and complications related to stent implantation, ${ }^{10,11}$ and the use of internal airway stents became controversial. The purposes of this study were to assess the outcome of this treatment in a relatively large group of patients and to define clear indications for airway stenting.

\section{Materials and Methods}

A retrospective review was conducted of all patients who had undergone airway stenting since 1995. Forty-two stents were inserted in 32 infants and children aged 1 to 64 months (mean 4.5 months). According to the site of stent implantation, the patients were divided into 
TABLE 1. Clinical data

\begin{tabular}{|c|c|c|c|c|}
\hline & $\begin{array}{c}\text { Group } \\
\text { A }\end{array}$ & $\begin{array}{c}\text { Group } \\
\text { B }\end{array}$ & $\begin{array}{c}\text { Group } \\
\text { C }\end{array}$ & Total \\
\hline Cases & 14 & 16 & 2 & 32 \\
\hline \multicolumn{5}{|l|}{ Type of stent } \\
\hline NiTi-ITS & 4 & - & - & \\
\hline Palmaz P-154 & 9 & 21 & 4 & \\
\hline Palmaz P-204 & 3 & & & \\
\hline No. of stents & 16 & 22 & 4 & 42 \\
\hline Age at stenting (mo, mean) & 8.1 & 3.1 & 2.2 & \\
\hline \multicolumn{5}{|l|}{ Associated cardiac disease } \\
\hline Transposition of the great arteries & 1 & 3 & - & 4 \\
\hline Complete atrioventricular canal & 2 & 6 & 2 & 10 \\
\hline Hypoplastic left heart syndrome & 1 & 4 & - & 5 \\
\hline Cardiomyopathy & 3 & - & - & 3 \\
\hline Vascular ring & 3 & - & - & 3 \\
\hline \multicolumn{5}{|l|}{ Other associated disease } \\
\hline Trisomy 18 & 3 & 6 & - & 9 \\
\hline VATER & 6 & 1 & - & 7 \\
\hline Severe failure to thrive & 10 & 15 & 2 & 27 \\
\hline Other & 6 & 3 & - & 9 \\
\hline \multicolumn{5}{|l|}{ Indication } \\
\hline Inability to extubate & 10 & 11 & 2 & 23 \\
\hline Recurrent cyanotic spells & 4 & 5 & - & 9 \\
\hline Recurrent pneumonia & 2 & 6 & 1 & 9 \\
\hline
\end{tabular}

All data represent numbers of patients unless otherwise specified. VATER, Vertebral defects, imperforate anus, tracheoesophageal fistula, and radial and renal dysplasia.

three groups (Table 1): group A $(\mathrm{n}=14)$, trachea; group B $(\mathrm{n}=$ 16), major bronchi; and group $C(n=2)$, trachea and bronchi. In 7 patients in group A, 3 in group B, and 2 in group C, more than one stent was needed to maintain a stable, open airway. Stents were placed by rigid bronchoscopy with the patients under general anesthesia. The exact site for stenting was determined by the simultaneous use of endoscopy and fluoroscopy. Some adjustment of the stent's position at the completion of the procedure was possible by gentle traction with grasping forceps.

Two different stents were used in all three groups. NiTi-ITS, a shape memory stent made of nitinol, an alloy with "shape memory effect" (type I) ${ }^{12}$ was used in 4 patients, all in group A. A Palmaz 37 stent (type II; Johnson \& Johnson International Systems Co, Warren, NJ) was used in 28 patients. We used the medium size Palmaz stents P-154 and P-204 with diameter of $3 \mathrm{~mm}$ and lengths of $14.7 \mathrm{~mm}$ and 19.6, $\mathrm{mm}$ respectively, and expanded diameters of 4 to $9 \mathrm{~mm}$. The most frequent indication for stenting was inability to extubate: 10 infants in group A, 11 in group B, and infants in group $\mathrm{C}$. The mean period of ventilation before the stent placement was 12 weeks (range 8-16 weeks). One patient underwent segmental resection, and 2 underwent tracheal autografts, all in group A. Among the other 29 patients, airway obstruction was associated with malacia in 7 and extrinsic compression by a major vessel or hypertrophic heart in 22 .

Severe cardiac disease was a frequent associated problem and was present in 10 infants in group A, 13 in group B, and in 2 infants in group C. Other cardiac malformations included transpo-
TABLE 2. Clinical results of airway stenting

\begin{tabular}{lrrrr}
\hline & Group & Group & Group \\
& A & B & C & Total \\
\hline Immediate relief of airway obstruction & 13 & 15 & 2 & 30 \\
Stenting failure & 1 & 1 & & 2 \\
Weaned from mechanical ventilation & 10 & 11 & 2 & 23 \\
Stent in place (mo, mean) & 11.2 & 14.1 & 4.1 & \\
Complications & & & & \\
$\quad$ Granulation & 9 & 10 & 1 & 20 \\
$\quad$ Airway obstruction & 6 & - & - & 6 \\
$\quad$ Stent migration & 2 & 1 & - & 2 \\
$\quad$ Tracheoesophageal fistula & 1 & - & - & 1 \\
$\quad$ Death* & 2 & - & - & 2 \\
No. of stents removed & 7 & 4 & - & 11 \\
Last follow-up & & & & \\
$\quad$ Alive and well with stent removed & 7 & 4 & - & 11 \\
$\quad$ Alive and well with stent in place & 2 & 4 & - & 6 \\
$\quad$ Dead* & 7 & 6 & 4 & 15 \\
\hline
\end{tabular}

All data represent numbers of patients unless otherwise specified. *In 13 cases, death was not related to airway stenting, but to the associated disease.

sition of the 2 great arteries ( 3 patients), hypoplastic left heart syndrome (5 patients), vascular ring (3 patients), and cardiomyopathy ( 3 infants) in group A. In all three groups, 25 patients had an additional major disease; 21 had more than one associated disease (Table 1). There were 8 infants each with complete atrioventricular canal in groups $\mathrm{B}$ and $\mathrm{C}$ and 2 in group $\mathrm{A}$.

Stent removal was performed in the operating room through a rigid bronchoscope under fluoroscopic control with general anesthesia. A scrub nurse with an open thoracotomy set was present in the room. Extracorporeal membrane oxygenation or a bypass machine were not used for backup. Toothed grasping forceps were used to hold the upper end of the stent. The handle of the forceps was rotated to decrease the diameter of the stent and allow it to break loose from the tracheal wall. Usually, significant force had to be applied to detach the stent from the airway mucosa. The stent was then brought into the lumen of the bronchoscope, and the bronchoscope with the stent inside was withdrawn from the airway. Once the stent was removed, little bleeding was noted; such bleeding stopped spontaneously in all cases.

In this study, there were no clearly defined guidelines for stent removal. When the stent was well tolerated, it was left in place for at least 6 to 8 months. Stents were removed whenever airway obstruction occurred, or when the major cardiovascular disease was overcome, respiratory symptoms had resolved, and the airway proximal and distal to the stented segment appeared stable on bronchoscopy.

The families were advised of the novel nature of this method of treatment. Informed consent outlining possible complications, including the obscure long-term results, was obtained in all cases.

\section{Results}

There were no complications related to stent insertion, and stent placement was well tolerated by all patients (Table 2). Immediate relief of airway obstruction was achieved in 30 
patients. Among the 23 patients in whom the original indication for stent insertion was inability to wean from ventilation, 21 could be weaned from mechanical ventilation within 24 to 48 hours after the airway stenting. In 2 infants, 1 each in groups $\mathrm{A}$ and $\mathrm{B}$, the airway stenting failed to improve airway obstruction. One infant in group A with severe subglottic stenosis eventually required tracheostomy after the tracheal stenting. The second patient (group B), a 3 -year-old infant with complete atrioventricular canal and hypoplastic right ventricle, had severe, isolated, long-segment left main bronchomalacia. Repeated attempts to relieve the obstruction with two internal stents failed. Almost complete atelectasis of the left lung subsequently developed.

Excessive granulation formation was the prominent complication of airway stenting. The upper ends of the stents in groups $\mathrm{B}$ and $\mathrm{C}$ and the lower ends of the stents in group $\mathrm{A}$ were the sites of the most exuberant granulation. Excessive granulation tissue developed in all 4 patients with type I (nitinol) stents, protruding into the lumen of the trachea between the metallic spiral arms of the stents.

In only 6 patients had the stent epithelialized well by 20 to 60 days. At follow-up bronchoscopy in those patients, the stents had become almost fully covered by respiratory mucosa, without any evidence of granulation. In 20 patients, 9 in group A and 10 in group B, the inflammatory reaction did not result in significant airway obstruction or infection, but those patients did require repeated bronchoscopy. The granulation tissue was removed by scraping it with the sharp edges of the rigid bronchoscope suction and sometimes by use of bronchoscopic grasping forceps. In 6 patients, all from group A, the granulation and inflammatory reaction generated severe airway obstruction. In only 2 of those patients could the extreme respiratory distress be relieved by bronchoscopic manipulation; in the other 4 , the stents had to be removed. In 2 of those 4, the stents could not be removed through the bronchoscope, and emergency division of the trachea through a midsternotomy was performed. In a 3-month-old infant who had undergone segmental tracheal resection for congenital stenosis, the stent could not be removed even after opening the trachea, and the patient died during the attempt to remove the stent. In another infant in group A with a type I stent, excessive granulation produced severe airway obstruction. The infant died in another hospital before any attempt was made to relieve the obstruction. This might possibly have been avoided had bronchoscopy and immediate removal of the stent, or even tracheostomy, been attempted at presentation.

In 2 patients in group $A$ and 1 in group B, there was mild stent migration, which necessitated repositioning of the stent in 1 case and stent removal in the other 2. Eleven stents were removed from 10 children. In group $\mathrm{A}$, the stents remained in place between 4 and 72 months (mean 11.2 months); in group B, they remained between 11.2 and 40.2 months (mean 14.1 months); and in group $\mathrm{C}$, they remained between 2.2 and 8.2 months (mean 4.1 months). After the stents were removed, a small amount of mucosal bleeding was usually encountered; this stopped spontaneously within minutes. Considerable care was necessary in manipulating the stent and keeping the airway clear of blood after removal. Once the stent was successfully removed, however, no complications appeared in any of our patients.

Removal of the stent was more difficult in group A patients with excessive granulation and in those in whom the stent was embedded into the airway mucosa. There was no correlation between complications and the length of time the stents were in situ.

In 1 patient, a recurrent tracheoesophageal fistula developed 4 years after the original repair and 1 year after the tracheal stenting. The stent was removed, and the fistula was subsequently successfully repaired. Before the original repair through the right fourth intercostals space, the fistula was identified with bronchoscopy, and a Fogarty $2 \mathrm{~F}$ catheter was inserted through it into the esophagus. This was helpful in locating the fistula, which was than divided, and each side was closed with fine sutures. A pleural intercostal muscle flap was placed between the tracheal and esophageal fistula closures.

As of the most recent follow-up, there are 11 children alive and well whose stents were removed, 4 from group A and 7 from group B. Six patients are alive and well with stents in place, 2 from group A and 4 from group B. Fifteen patients died during the follow-up period; in 13 cases, death was related to the associated diseases (7 from group A, 4 from group B, and 2 from group C).

Seven patients died free of airway problems; the other 4 still had persistent mild airway problems, none of them necessitating reintubation. Two patients in group B underwent tracheostomy to relieve upper airway obstruction.

\section{Discussion}

The treatment of serious airway obstruction caused by tracheobronchomalacia, intractable airway stenosis, or airway compression by other organs is, even today, a forbidding challenge. To date, many therapeutic approaches have been suggested, none of which has been widely adopted for pediatric patients. ${ }^{3}$ The various surgical techniques of patching, resecting, suspending, or external stenting of the malacic airway segment have not been widely embraced. On the other hand, implantation of an endoluminal stent that will give rigid support to the malacic segment and thereby prevent inspiratory collapse seems to be a logical and practical option. Silicone elastomer and absorbable stents currently used in adult patients have external diameters that preclude their use in children. Other stents, such as stainless 
steel springs covered with silicone rubber, have been abandoned because of technical problems. ${ }^{13}$

Nowadays it is generally accepted that the technique of stent insertion is straightforward. The endoscopic equipment is available in most pediatric surgical units, and most of the different types of stent are readily obtainable. In most cases, the respiratory relief is dramatic and gratifying.

In this study, 23 patients were able to be extubated shortly after airway stenting. Some were tube dependent for a few months. There were no complications related to stent insertion in any of the patients. However, there are still several very significant, unresolved problems associated with the metallic stents that make their use questionable and controversial. Although the length of the stent can be accurately determined at bronchoscopy, it is our experience that the decision regarding the appropriate expanded diameter of the stent is much more difficult. A balloon that is too small will not expand the stent to reach the wall of the airway and will lead to stent displacement. A balloon diameter that is too large may overexpand the stent and apply excessive pressure on the wall of the airway, leading to ischemia or an aggressive inflammatory reaction. In this study, the selfexpanding titanium alloy stent resulted in excessive granulation in all 4 patients, and although extraction of the stent was easy, its use was abandoned until the implantation method could be revised.

Because one is inserting foreign material into the airway, it would be ideal to remove a stent after it was no longer needed. Although we were able to remove the stent in 11 cases, the danger of the removal must be reemphasized, and removal of internal stents, particularly in patients in group A, can be a very serious, even life-threatening, procedure. As noted, 1 infant in this series died during the attempt to remove the stent, and another required tracheostomy after tracheal division. All possible measures must be on hand to relieve life-threatening airway obstruction that may occur during stent removal. Stents that are completely covered by airway mucosa, or those with excessive granulation, specifically in group A, carry a greater risk of complications during attempted removal. Once an attempt is being made to remove the stent, it is very difficult to abandon the procedure. At that point, if airway obstruction occurs and the stent cannot be removed, possible access to the trachea would be through the neck or immediate midsternotomy. Other measures, such as extracorporeal membrane oxygenation or cardiopulmonary bypass, as suggested by others, ${ }^{14}$ do not seem to be applicable in these cases. It is possible, however, that, in group B patients, one-lung intubation might allow enough time to apply one of those procedures.

The question of the optimal period of airway stenting is unclear. In symptom-free patients, especially if there is concern about the safety of the patient during stent removal, a rational approach would be to leave it in place and undertake periodic dilatations. The long-term effect of stenting on airway growth is another concern. To date, no problems have been noted, but the number of children studied is small, ${ }^{2}$ and the longest times a stent was in place in this study were 6 years in 1 patient in group A and 4 years in 2 patients in group B.

The most prominent and distressing problem encountered was the tendency of the Palmaz stent to cause obstructing granulation tissue over the stent. This resulted in severe airway obstruction in 6 children, all in group A, and necessitated emergency stent removal. Another 20 patients required repeated bronchoscopies to clear the granulation tissue. Granulation was more common in patients in group A $(n=15)$ than in groups $B$ and $\mathrm{C}(\mathrm{n}=11)$. In only 6 patients in this study was the stent well covered by respiratory mucosa without any evidence of granulation. There is no obvious explanation for the excessive granulation formation with metallic stents. Some have suggested that it is related to preoperative tracheal inflammation, whereas others ${ }^{1}$ believe that the excessive granulation is due to overexpansion of the stent. There are limited data in the pediatric population to support the latter contention; in our study we could not find any clear correlation between airway overexpansion and excessive granulation. Tracheal inflammation was not regarded as a contraindication to stent placement in this study.

Other problems occurring after stent insertion are infrequent, although they can be severe or even fatal. In this series, 3 children with stent migration and 1 with recurrent tracheoesophageal fistula were treated successfully by repositioning of the stent in 1 case and removal of the stents in 3 . Cook and associates ${ }^{11}$ have reported a fatal complication of aortobronchial fistula in a 14-yearold boy. Others have reported complications associated with stents, including dysphagia and severe hemoptysis.

In an effort to decrease these complications, various types of stent are currently undergoing investigation. The ideal pediatric airway stent remains elusive, and each stent type has its own advantages and disadvantages. ${ }^{14}$ Stent use in the treatment of pediatric airway obstruction should be restricted to the limited situations in which conventional initial therapy has failed. Our results with the implantation of the currently available airway metallic stents indicate that although it is an effective method of treatment, it is associated with a high complication rate, particularly in the case of tracheal stenting. The nitinol (type I) stent was associated with severe problems of airway obstruction, and although the stent can easily be extracted, its use was suspended pending further improvement in its design.

Extraction of the stent is difficult and dangerous, and the long-term results are still unclear. Until better stents 
can be developed, their use should be limited to patients critically ill with stenosis or compression that cannot be resolved safely with current surgical procedures.

\section{References}

1. Filler RM, Forte V, Fraga JC, Matute J. The use of expandable metallic airway stents for tracheobronchial obstruction in children. J Pediatr Surg. 1995;30:1050-6.

2. Filler RM, Forte V, Chait P. Tracheobronchial stenting for the treatment of airway obstruction. J Pediatr Surg. 1998;33:304-11.

3. Santoro G, Picardo S, Testa G, Formigari R, Marianeschi S, Catena G, et al. Balloon expandable metallic stents in the management of tracheomalacia in neonates. J Thorac Cardiovasc Surg. 1995;110:1145-8.

4. Furman RH, Backer CL, Dunham ME, Donaldson J, Mavroudis C, Holinger LD. The use of balloon expandable metallic stents in the treatment of pediatric tracheomalacia and bronchomalacia. Arch Otolaryngol Head Neck Surg. 1999;125:203-7.

5. Maeda K, Yasufuku M, Yamamoto T. A new approach to the treatment of congenital tracheal stenosis: balloon tracheoplasty and expandable metallic stenting. J Pediatr Surg. 2001;36:1646-9.

6. Kumar P, Roy A, Goldstraw P, et al. Airway obstruction and ventilator dependency in young children with congenital cardiac defects: a role for self-expanding metal stents. Intensive Care Med. 2002;28:190-5.

7. Nicolai T, Huber RM, Reiter K, Merkenschlager A, Hautmann H, Mantel K. Metal airway stent implantation in children: follow-up of seven children. Pediatr Pulmonol. 2001;31:289-96.

8. Tsugawa C, Nishijima E, Muraji T, Yoshimura M, Tsubota N, Asano $\mathrm{H}$. A shape memory airway stent for tracheobronchomalacia in children: an experimental and clinical study. J Pediatr Surg. 1997;32:50-3.

9. Nashef SA, Dromer C, Velly JF, Labrousse L, Couraud L. Expanding wire stents in benign tracheobronchial disease: indications and complications. Ann Thorac Surg. 1992;54:937-40.

10. Perini S, Gordon RL, Golden JA, LaBerge JM, Wilson MW, Kerlan RK Jr. Deformation and migration of Palmaz stents after placement in the tracheobronchial tree. J Vasc Interv Radiol. 1999;10:209-15.

11. Cook CH, Bhattachargya, King DR. Aortobronchial fistula after expandable metal stent insertion for pediatric bronchomalacia. J Pediatr Surg. 1998;33:1306-8.

12. Vinograd I, Klin B, Brosh T, Weinberg M, Flomenblit Y, Nevo Z. A new intratracheal stent made from nitinol, an alloy with "shape memory effect." J Thorac Cardiovasc Surg. 1994;107:1255-61.

13. Loeff DS, Filler RM, Gorenstein A, Ein S, Philippart A, Bahoric A, et al. A new intratracheal stent for tracheobronchial reconstruction: experimental and clinical studies. J Pediatr Surg. 1988;23:1173-7.

14. Jacobs JP, Quintessenza JA, Botero LM, van Gelder HM, Giroud JM, Elliott MJ, et al. The role of airway stents in the management of pediatric tracheal, carinal, and bronchial disease. Eur J Cardiothorac Surg. 2000;18:505-12.

Access to The Journal of Thoracic and Cardiovascular Surgery Online is reserved for print subscribers!

Full-text access to The Journal of Thoracic and Cardiovascular Surgery Online is available for all print subscribers. To activate your individual online subscription, please visit The Journal of Thoracic and Cardiovascular Surgery Online, point your browser to http://www.mosby.com/jtcvs, follow the prompts to activate your online access, and follow the instructions. To activate your account, you will need your subscriber account number, which you can find on your mailing label (note: the number of digits in your subscriber account number varies from 6 to 10). See the example below in which the subscriber account number has been circled:

\section{Sample mailing label}

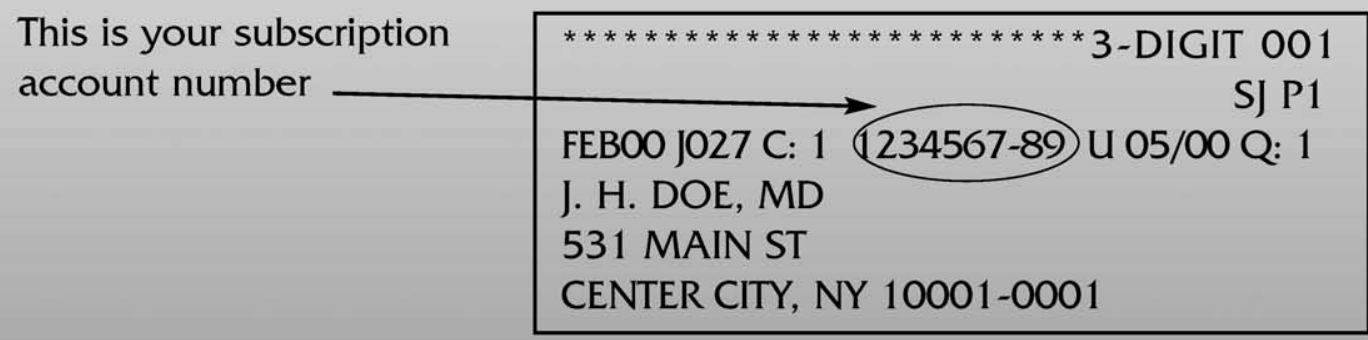

Personal subscriptions to The Journal of Thoracic and Cardiovascular Surgery Online are for individual use only and may not be transferred. Use of The Journal of Thoracic and Cardiovascular Surgery Online is subject to agreement to the terms and conditions as indicated online. 